\title{
Chapter 8 \\ Indigenist Leadership in Academia: \\ Towards an Aspirational Model \\ of Mindful Servant Leadership
}

\author{
Kerrie E. Doyle, Catherine Hungerford, Chris Pitt, Paul Saunders, \\ and Kyar Wilkey
}

\section{Introduction}

The tertiary education landscape in Australia has changed over the past decade, in line with developments in other occupational settings and environments across the western world (Bienen, 2012). Australian universities are now more performancebased (Guthrie \& Neumann, 2007); have insecure, non-government sources of funding (Moll \& Hoque, 2011); place a strong emphasis on globalisation (Stromquist \& Monkman, 2014); and have modified the way in which they support Indigenous programs (Gunstone, 2008). These kinds of changes suggest the need for academics, including Indigenous academics, to demonstrate strong leadership and management skills and abilities. For Indigenous academics, these requirements are in addition to the challenges related to 'being black in white spaces' (see Asmar, Mercier, \& Page, 2009; White, 2009), thereby increasing the pressure not only to lead but also to be seen to lead. There is a need, then, to develop indigenist leadership models that is rigorously based on evidence and best practice.

Leadership is a concept that has arguably existed since humans were required to work together to achieve a common goal. Even so, 'leadership' is a contested term (Sun \& Anderson, 2012), a situation that suggests diverse contexts require different leadership styles (Voon, Lo, Ngui, \& Ayob, 2011). Indeed, to be an effective

\footnotetext{
K. E. Doyle (殴

School of Medicine, Western Sydney University, Sydney, NSW, Australia

e-mail: AuntyKerrie.Doyle@westernsydney.edu.au

C. Hungerford

School of Nursing, Midwifery and Indigenous Health, Charles Sturt University, Bathurst, Australia

C. Pitt

Aboriginal Health and Wellbeing Clinical Academic Group, University of NSW, Kensington, Australia

P. Saunders $\cdot$ K. Wilkey

Translational Health Research Institute, Western Sydney University, Sydney, NSW, Australia
}

(C) The Author(s) 2020

J. Frawley et al. (eds.), Cultural Competence and the Higher Education Sector, https://doi.org/10.1007/978-981-15-5362-2_8 
leader requires consideration of the salient concepts informing leadership theories developed by recognised experts (Dotlich, Noel, \& Walker, 2011). Consideration of these theories will also allow Indigenous individuals to develop a personalised model of academic and community leadership.

Merging professional and community leadership styles, however, may be problematic for some Indigenous people (White, 2010). For example, Indigenous communities and places, like other colonised places, can sometimes be violent, contested spaces (Cheers et al., 2006; McCalman, Tsey, Kitau, \& McGinty, 2012; McIlwaine \& Moser, 2001), that need effective, life-affirming leaders. Leadership of such communities is usually an all-hours commitment with pursuant burnout occurring in individual leaders (Santoro \& Reid, 2006). Recognising the exponential stress of 'leading' in a community as well as at work, we, therefore, argue there is a need for an Indigenous leadership model that is aspirational.

If one concurs with leadership theorists such as MacBeath and Dempster (2008) that leadership is a learned trait or set of behaviours, then becoming an effective leader requires consideration of a range of factors. These factors include the different types of leadership styles, together with the motivations of leaders and also the communities produced by the teams. Reviewing leadership styles that could fit in an organisation or community would allow potential leaders to distil the skills and behaviours of already established effective leaders, and thereby create an individuated, indigenist leadership model that matches personal resources to professional requirements.

\section{Theoretical Review}

Leadership is a complex function of other organisational, social, personal, and cultural processes (Boldon, 2004). Leadership depends on a process of influence, and the ability of a leader to inspire their team to work towards group goals, with researchers still undecided as to whether leadership is a personality trait, a positional power issue, a philosophical argument, or even an embodiment issue (Grint, 2004).

Leadership theorists often differ when discussing styles and models, but most agree that all leaders must have a set of demonstrable values and behaviours. These values and behaviours include: being cooperative and optimistic, with a capacity to lead by example (reflecting social motivation) (Gächter, Nosenzo, Renner, \& Sefton, 2012); having trustworthiness, integrity, emotional intelligence (Goleman, Welch, \& Welch, 2012); possessing the capacity to actively contribute as well as being at ease with power and courageous (Buchele, 2011); being good at maintaining relationships, having vision and being forward-looking, possessing a combination of behaviours that show the leader is inspiring, decisive, able to provide direction, honest, competent (Kouzes \& Posner, 2011); and finally, being authentic, altruistic, collective (Ciulla, 2013). Besides providing this list of values, which arguably characterises the most successful or prospective leaders some theorists also provide lists of prescriptive recommendations for action (Bolden, Hawkins, Gosling, \& Taylor, 2011; Detsky, 2010; Sinclair, 2014). Such lists can, therefore, seem daunting. At the 
Table 8.1 Core values of Indigenous communities (after Shannon et al., 2005)

\begin{tabular}{l|l}
\hline Reciprocity & $\begin{array}{l}\text { Obligation to achieve an equitable distribution of resources and } \\
\text { benefits }\end{array}$ \\
\hline Respect & $\begin{array}{l}\text { Trust, cooperation, valuing, and respect for human dignity; } \\
\text { unconditional positive regard, consultative }\end{array}$ \\
\hline Equality & $\begin{array}{l}\text { Considering all people to be of equal value, act with fairness and } \\
\text { justice }\end{array}$ \\
\hline Responsibility & Obligation to do no harm \\
\hline Survival and protection & Protection of culture, non-exploitative \\
\hline Spirit and integrity & $\begin{array}{l}\text { Overarching values that bind the other five values into a coherent } \\
\text { whole }\end{array}$ \\
\hline
\end{tabular}

same time, however, they also suggest commonalities-for example, the characteristics of courage, integrity, emotional intelligence (not necessarily expressed as such, but able to be so labelled) are common, with some theorists arguing that such values can be practiced and learned (Sinkula, Baker, \& Noordewier, 1997).

While it is well recognised that Indigenous Australians are not homogenous (Doyle, 2011), shared values have been identified across many Indigenous Australian communities (Jamieson et al., 2012; Shannon, Shibasaki, \& Australian Health Ethics Committee 2005; Walker, Fredericks, Mills, \& Anderson, 2014). These shared values are also reflected in the national ethical guidelines for research in Indigenous communities (see Fletcher, Shannon, \& Dunbar, 2008), providing a rigorous framework to guide any proposed leadership model. The values are listed in Table 8.1.

In this context, it is important to note that experts in indigenist research claim that localised models of research, suited to the context and community of interest, constitute a methodologically sound approach to the conduct of research (Foley, 2003; Martin, 2003; Nakata, 1998; Rigney, 2006a, 2006b; Smith, 1999; West, Stewart, Foster, \& Usher, 2012). It could well be argued, then, that it is equally as appropriate to modify indigenist leadership models to suit the context, community and of course, the leader.

This type of model creation usually builds on existing models. For this reason, it is also necessary to consider appropriate styles of leadership for Indigenous peoples. Bolden et al. (2011), for instance, describe the genealogy of Eastern and Westernstyle leadership philosophies from Lao Tze and Socrates, to modern presidents of the USA, and by doing so, illustrate how the adaption of leadership models occurs to suit cultures. Even so, the process of distilling the core components of a leadership model to create an individualised model can be a traumatic experience for a novice leader and is described by Bennis and Thomas (2002) as a crucible, where the refining aspects of experiences of diversity that transform individuals into strong leaders.

Even so, there is a missing space when considering Indigenous leadership models, which perhaps explains why some indigenist theorists use their own experience, together with community morés and opinions, to create their models. For example, Sinclair (2007) uses her leadership experience as an Indigenous Australian academic to create a theoretical framework for women in leadership positions; Fredericks 
(2009) shares her experiences and in doing so demonstrates her epistemology of Indigenous peoples' leadership participation in universities; and White (2009) completed doctoral research on the journey to leadership for university-educated Indigenous Australian women. Each of these women created a modified leadership style best suited to their situational and contextual needs. Given the evidence of melding or creating models best suited to the leader, community and context, it is, therefore, appropriate to consider motivation to lead in a manner that gives rise to success and thereby create evidence to foster model creation.

\section{Motivated to Lead: Setting the Scene}

Action is often preferable to inaction (Bolden, 2004). However, reaction without an understanding of the underlying principles and assumptions about leadership demonstrates low emotional intelligence, reduces a leader's effectiveness and risks causing damage (Prati, Douglas, Ferris, Ammeter, \& Buckley, 2003) to an organisation or community. Leadership can, therefore, be seen as a key enabler for community and organisation success, and a measure of that enablement is the level of motivation of individuals or groups, in communities and organisations, to achieve success.

Studies of achievement motivation focus on either the individual motives of achievers (McClelland, 1987) or engagers (Attridge, 2009), or the motives of persons reacting 'to' the achievements of others (Feather, 1994; Lockwood, 2007). However, it is also important to consider the reactions to, and of, the leader in successful organisations and communities, and how the leader responds to the reaction of their group members (Carr, 2006). The reaction of the community to the perceived success of a leader is pivotal to the social and emotional wellbeing of the whole community. For example, a celebratory response to a successful leader, however defined, would indicate the community members have a healthy self-esteem with a sense of control based within the community, and collective emotional resilience (Müller \& Turner, 2010).

\section{Social Identity and Workplace Culture}

Leading a successful team or community group requires an understanding of culture (Jogulu, 2010), not simply ethnicity. Being able to unpack the cultural morés of an organisation or community is quintessential to successfully achieving one's aims and requires an understanding of the role of social identity (Tajfel, 2010) in group formation and maintenance (Schmid, Hewstone, \& Al Ramiah, 2011). For example, personal success of one group member can attract hostility from other group members (Rundle-Gardiner \& Carr, 2005), and a leader is usually seen as having some degree of personal success (Ciulla, 2013). This can be problematic in Indigenous communities where lateral violence is endemic (Wingard, 2010), given that one of the triggers 
of such violence is the 'tall poppy syndrome' (Gooda, 2007; Langton, 2008). Where tension as a function of this syndrome exists in workplace and communities, acts of psychological violence on individuals who were supposedly 'big-noting' (or bragging about) themselves can occur as an act of covert lateral violence (Johnson \& Rea, 2009), and are a risk to an individual's mental wellbeing (Turney, 2003). It is axiomatic that psychological distress in any sense is not profitable, on any level, for any organisation or community, therefore an ability to measure and identify workplace culture is an appropriate beginning to a leadership journey.

\section{The Motivational Gravity Grid: Measuring the Culture of 'Around Here'}

Measuring workplace culture is discourse-dependent (Schnurr, 2008) as researchers measure a variable or outcome of interest to themselves, such as religiosity and work performance (Petchsawang \& Duchon, 2012); gender and power (Stainback, Ratliff, \& Roscigno, 2011); or ethical/unethical behaviours (Parker \& Aitken, 2011). An effective measure of a workplace's global culture is Carr's (1995) measure of motivational gravity. The Motivational Grid Measure (see Fig. 8.1) is useful for organisational or community reflection, and to diagnose issues in a team (Carr \& MacLachlan, 1997). Importantly, the pictorial nature of the tool has long been validated in organisational settings (see, for example, Akuamoah-Boateng et al., 2003; Carr, Maclachlan, Zimba, \& Bowa, 1995; Smith \& Carr, 1997; Munro, Schumaker \& Carr, 2014). The Motivational Gravity grid measures attitudes towards achievement motivation for team members. Gravity can emanate from bosses (superiors, managers), as push-down/pull-up activities; or from peers and subordinates, expressed as pull-down/push-up activities. This creates a $2 \times 2$ grid where respondents can mark the predominant culture of their community of interest. These activities were caricatured in each quadrant, making it a visual tool where respondents mark his or her perceived 'hot spot' (Carr, 2006; Carr \& MacLachlan, 1997; Carr et al. 1995).

To gather evidence, promote discussion, and enable the development of a model of leadership best suited to local setting, workplace/community culture and needs to the leaders, teams and community, a quality improvement project was proposed, designed and implemented, with the aim to reviewing associated communication and motivational practices in a university setting. The decision was made to incorporate the Motivational Gravity Grid (Carr \& Mac Laughlan, 1997) into the project, with the purpose of informing findings and supporting development of the leadership model. Low-risk ethical approval was obtained from the university. 


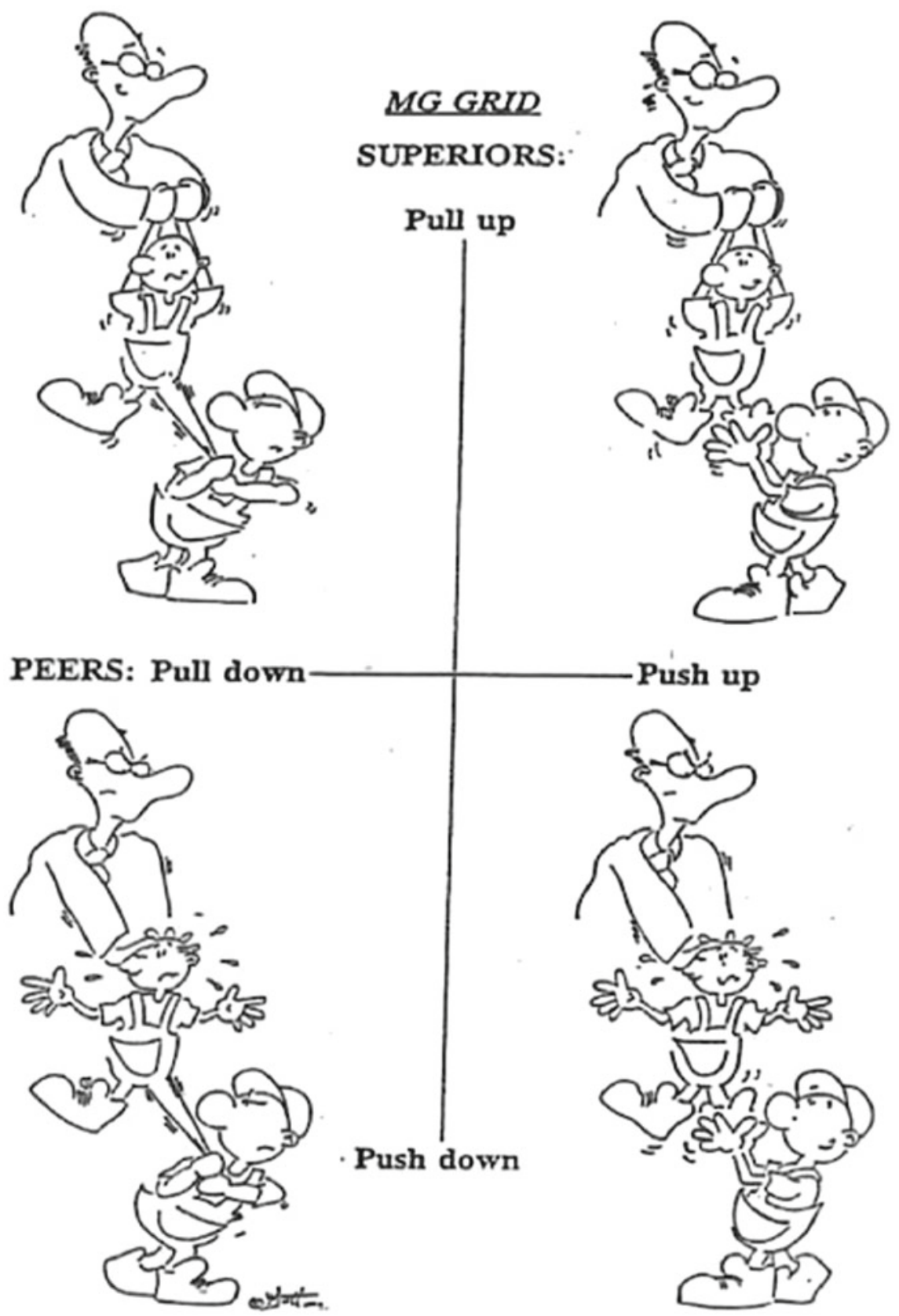

Fig. 8.1 The motivational gravity grid (Carr \& MacLachlan, 1997). Used with permission of the authors, 2019 


\section{Method}

The quality improvement project was undertaken using a mixed-methods approach, utilising quantitative and qualitative approaches. The quantitative part of the project utilised a Qualtrics questionnaire (e-survey), with a view to supporting ease of data capture and protecting confidentiality. It was anticipated that quantitative results would assist with providing an objective structure for the indigenist model of leadership. Likewise, the qualitative component included in-depth interviews, with a view to inducing findings through an analysis guided by specific objectives (Thomas, 2016) — in this case, identifying themes of indigenist leadership — and it was anticipated that the inductive theming of the finding would allow the findings to emerge from the frequent, dominant or significant codes inherent in the data (Fereday \& Muir-Cochrane, 2006).

The quantitative component of the research, the e-survey, was advertised on the university quality website. Using the resource shown in Fig. 8.2, participants were asked to put a spot where they preferred the culture (Y) to sit, and where they considered their workplace culture $(\mathrm{X})$ was best placed. Participants were then asked to consider how their position at work placed them in the culture of their community, or workplace/community $(\mathrm{O})$ intersect. In order to maintain confidentiality, the only demographics captured were gender and Indigeneity.

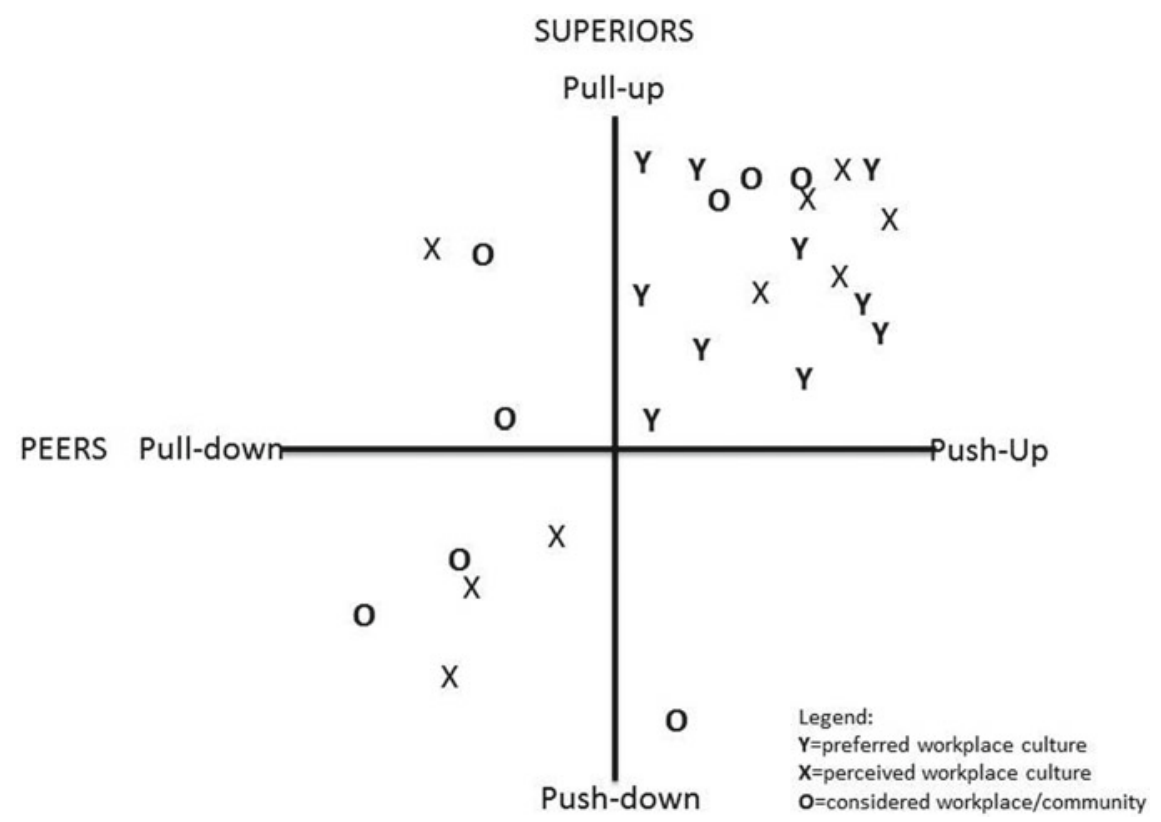

Fig. 8.2 Perceived workplace cultures of respondents $(n=10)$ 
Participants in the qualitative component of the research, the in-depth interviews, were drawn from volunteers who participated in the e-survey, with recruitment derived from a simple question at the end of the questionnaire about willingness to be interviewed and a request for contact details. Questions were open-ended and participants were asked to explore the characteristics of an effective Indigenous leader. With consent, the responses were recorded, transcribed (de-identified) and analysed thematically (Braun \& Clarke, 2006). The interviews were open-ended, and participants were asked to explore the qualities of an effective Indigenous leader. Interviews were conducted using a narrative, unstructured method, considered appropriate for interviewing Indigenous people (Boffa, King, McMullin, \& Long, 2011).

\section{Findings: Motivational Grid}

\section{Demographics}

Given this was a quality improvement project with a small team, there were only 10 respondents ( $n=6$ Indigenous academics and $n=4$ Indigenous staff, $M=4, F=6$ ).

\section{Perceived Workplace Culture}

While $100 \%$ ( $n=10)$ of respondents preferred to work in a pull-up/push culture, only $50 \%$ (five respondents) considered their workplace culture to be one where the supervisor and peers of that workplace demonstrated pull-up/push-up behaviours. Of these five, two had an Indigenous supervisor. One respondent felt the workplace culture was pull-up/pull-down and the remaining three considered they worked in the most non-productive workplace culture of pull-down/push-down. Respondents had differing experiences of the work/community culture intersect, with $30 \%(n=$ $3)$ reporting a pull-up/push-up culture, $20 \%(n=2)$ reporting a pull-up/pull-down culture, and the remaining $30 \%(n=3)$ reporting negative cultures (see Fig. 8.2). Participants were invited to participate in a narrative interview to consider the data. Of the 10 participants, six agreed to be interviewed.

\section{Findings: E-survey}

Six Indigenous participants of the e-survey agreed to be interviewed. Interviews were conducted using open-ended questions and a narrative, unstructured method, considered appropriate for interviewing Indigenous people (Boffa et al., 2011). The 
interviewer was an Indigenous woman academic from a different educational institution. Participants were shown the MG Grid (Carr \& MacLachlan, 1997) (see Fig. 8.1), given the results of the survey, then asked to describe the results from their perspective including consideration of the types of behaviours that might have informed the answers. Interview responses were coded into three main themes. These themes are now discussed, in turn.

\section{Theme One: Gravity of Non-indigenous Colleagues}

The first theme was labelled 'gravity of non-Indigenous colleagues' and described the push-down/pull-down culture. Respondents identifying the push-down/pull-factors revealed that the pull-down culture was a function of non-Indigenous colleagues appearing to be unsupportive of any perceived 'benefit' or promotion of an Indigenous person. The push-down culture was due to the lack of cultural proficiency, or understanding of Indigenous culture, in the workplace. While the change in university structure in most Australian universities has seen the embedding of Indigenous academics in faculties rather than Indigenous centres (Australian Government, 2011), this has led to most schools or colleges incorporating a single Indigenous academic. Working as a single representative of one's ethnicity increases the public gaze towards Indigenous people and, as all universities are microcosms of any society, the pushdown/pull-down result might be a function of covet racism from non-Indigenous colleagues and the system itself.

\section{Theme 2: Gravity of Community}

The second theme was also push-down/pull-down and labelled as the 'gravity of community'. The push-down scores were predominantly a function of the home community. Some Indigenous colleagues were beset by issues of lateral violence in the community and felt that community would resent their success, rather than celebrate it, and this gravity affected their motivation to achieve at their workplace. The 'push-down' scores were a function of the home community, with few exceptions in the workplace. This confirms that, for Indigenous people, there is a blurring of work or professional and community boundaries (see Kowanko et al., 2009), leading to burnout, which risks perceptions of Indigenous people having poorer personal and team motivation (Taylor \& Barling, 2004). 


\section{Theme 3: Gravity of Indigenous Supervisors}

The thirdtheme was a mixed response and labelled 'gravity of Indigenous supervisors'. While one Indigenous supervisor was an experienced manager and his team scored him as pull-up, the other two Indigenous leaders (not based in the university, but still considered part of the 'workplace culture' by participants) were scored as push-down. Two of the six Indigenous academics had a pull-up Indigenous supervisor, and these respondents believed that supervisor created an encouraging culture. For example, a respondent stated that she had frequently been encouraged to apply for higher grades and was supported in her attempts. The other respondent noted that the supervisor had actively sought out scholarships for her. They felt he 'stood-up' for them. The other respondent with her Indigenous supervisor, had a different experience, and felt she was being 'bullied' by the supervisor. This respondent reported a push-down culture that overwhelmed any push-up culture from her colleagues. An example of pull-down was bullying, and this respondent gave an example of being denied cultural leave or being told that applying for promotion was a 'waste of her time'.

Having Indigenous people in supervisory roles introduces another layer of complexity into the mix of work and community cultures. It might be expected that Indigenous people who gain a place of power in an organisation will develop a pull-up approach to their in-group, however, it is not always the case. The style of each of these leaders powerfully created the workplace culture for their teams, suggesting that an effective leader is able to filter out negativity in order to have a productive team, while maintaining their cultural morés.

\section{Findings: Interviews}

Interviewing the six Indigenous participants to identify the push/pull factors revealed that the push-down/pull-down culture existed for these participants as a result of a lack of support or cultural understanding from non-Indigenous colleagues and the workplace, as well as the issue of perceived lateral violence in the community.

\section{Preferred Core Values of Indigenous Leaders}

During these interviews, in order to clarify some of the themes, respondents were asked what qualities their supervisor demonstrated, or would demonstrate, an Indigenous pull-up culture. Responses included 'they would be there for us', 'he put us first-before the organisation,' and 'she should stick up for me'. Asked for an example of push-down behaviour from supervisors, one respondent reported her supervisor said she 'wasn't black enough' to have an identified position. 
Specifically, participants were invited to create and rank the qualities of their supervisor, or the qualities they would prefer their supervisors to have. Participants were invited to write the qualities they aspired to see in their leaders on post-it notes then place them in order of importance, or preference, on a shared board. These qualities were distilled down to five values: bravery, honesty, willingness to commit, liking the staff, and knowledge. Indigeneity was not seen as a value but, rather, a characteristic of individuals. Of the five values, the six respondents agreed that the four most salient were bravery, honesty, helping in any circumstance, and liking the staff. After discussion, these values were re-labelled as courage, integrity, service, and unconditional positive regard. These values reinforce the interconnectedness that underpins all Indigenous wellbeing (Moreton-Robinson, 2013).

\section{Preferred Behaviours of Indigenous Leaders}

Participants were invited to interrogate the findings to identify behaviours that leaders could engage in, which would demonstrate these four core values. Participants considered that it takes courage to defend team members or take their side when conflict occurred with non-Indigenous staff. Leaders could serve their team or staff members by recognising that Indigenous peoples often felt culturally lonely, working in isolation in the academy and, as such, the need to promote resilience by preventing Indigenous staff from being over-utilised as cultural encyclopedia. Participants also noted that demonstrating integrity would include keeping one's word. Unconditional positive regard is similar to interconnectedness, particularly salient in the need for Indigenous leader to both be seen as leaders and servants of a community (Laverick, Hill, Akenson, \& Corrie, 2009). Interestingly, these values and behaviours suggested many similarities to servant leadership. It was therefore decided to explore the appropriateness of exploring this model of leadership for Indigenous leaders.

\section{Discussion}

In this section, we discuss the findings of the research in light of the research literature. This includes the notions of servant leadership and mindfulness. Through these lenses, we also look forward to an indigenist aspirational model of mindful leadership. 


\section{Servant Leadership}

Servant leadership was introduced in the 1970s by Greenleaf (Greenleaf, 1977). He recognised that individuals are products of their history, a sentiment that resonates with postcolonial peoples (Bailey, 2012). Cultural congruence is important for Indigenous people in any leadership position (Naquin et al., 2008), and Spears' (2004) 10 characteristics of servant leadership_listening, empathy, healing, awareness, persuasion, conceptualisation, foresight, stewardship, commitment to the growth of people, and building community - appear to be a good fit for the findings of this study of courage, integrity, service, and unconditional positive regard. A 'social identity' approach (after Tajfel, 2010; Ciulla, 2013; Bolden et al., 2011) to leadership also posits that people will not be regarded as leaders unless they are perceived to be working on behalf of the community, helping to frame the identity of the community, and putting in place structures and processes that further the interests of the community (Bolden et al., 2012).

Academic leaders need to be able to demonstrate and model independence and develop expertise in their academic field (Vilkinas \& Ladyshewsky, 2012), with such modelling a means of developing a deputation for leadership. This is what reputations are built on. However, currently, no leader in academia can avoid management responsibilities (Middlehurst, 2013), with academic management requiring a different skill set to leadership capabilities. For example, academic managers must have the ability to define objectives that meet the organisational, professional and individual goals; and organise and allocate academic tasks and processes. Such work requires a working knowledge of academic management practices.

According to Bolden et al. (2012, p. 2) the integration of management and leadership in academic settings requires leaders to do the following:

a) provide and protect an environment that enables productive academic work; b) support and develop a sense of shared academic values and identity; c) accomplish "boundary spanning" on behalf of individuals and work groups (boundary spanning here refers to the ability to create opportunities for external relatedness, getting things done via institutional administrations, mentoring colleagues into wider spheres of engagement.

This demonstrates the importance of linking the needs of community and the wants of workplace which, in turn, requires Indigenous individuals to walk 'with a foot in both camps.' Bolden et al.'s (2012) recommendations for effective academic leadership include being able to sit under a servant leadership model that comprises social identity theory. For example, a servant leadership model that promotes selfleadership (Bolden et al., 2011) and still emphasises engagement with individuals external to the primary setting of the workplace might suit Indigenous leaders. While individuals must be seen to fight for a common cause, offer inspiration and/or represent exemplary intellectual and professional standards (Bolden et al., 2012) in order to inspire followship, this does not mean that leaders hold leadership all the time and in all circumstances. Leadership can be located in teams, for example, especially in an enabling environment with a sense of purpose and boundary spanning (Bolden et al., 2012). 
Bolden et al.'s (2012) recommendations for effective academic leadership include being able to sit under a servant leadership model that comprises social identity theory. For example, a servant leadership model that promotes self-leadership (Bolden et al., 2011) and still emphasises engagement with individuals external to the primary setting of the workplace might suit Indigenous leaders. While individuals must be seen to fight for a common cause, offer inspiration, and/or represent exemplary intellectual and professional standards (Bolden et al., 2012) to inspire followship, this does not mean that leaders also hold leadership at all times and in all circumstances. Leadership can be located in teams, for example, especially in an enabling environment, with a sense of purpose and boundary spanning (Bolden et al., 2012).

Additional recommendations by Bolden et al. (2012) include the notion of leadership plasticity, which includes Kenny's (2006) notions of flexibility in leadership and being moulded to the tasks required. This also involves uses the potential or existing leaders in the community, while leaders need not be in a position of leadership (Kenny, 2006). Importantly, as a First Nations Canadian Indigenous woman, Kenny created a grounded theory of leadership that allowed her cultural morés to inform her leadership styles (Kenny, 2004). She agrees with Bolden et al. (2012) that leadership is not necessarily based on the individual but also can shift to other community members as the need arises (Kenny, 2012). A leader immersed in the philosophy of 'servant' would also understand this. At the same time, considering personal values in community and organisational settings is also an example of mindfulness.

\section{Mindfulness}

Mindfulness is a psychotherapeutic concept designed to encourage people to "be present" (Brown \& Ryan, 2003). Being present means to be in the moment with what is occurring around you. Being present is also a very Indigenous concept, as it is the same as 'kanyini,' one of the pillars of Indigenous culture (Fernandes, 2009); kanyini is a concept from the Pitjanjatjara people that means 'holding everything,' or 'keeping everything together' (Priest, King, Brown, Nangala, \& Nangala, 2007). 'Being present as a leader is considered to be mindful leadership' (Pipe \& Bortz, 2009).

Sinclair (2014) describes mindful leadership as 'mobilising and supporting others in a way that is deeply present, connected' (p. 10), and sums up mindful leadership as leading with 'less ego.' This also aligns with a servant leadership style, as both styles rely on 'being with others in ways that does not use them for [one's] own purposes' (Sinclair, 2014: 12). Mindful leadership considers the self and the psychological skill set of leading, such as the ability to influence, intra/interpersonal and consulting skills (Burke, Cho, \& Wright, 2008). In this way, self becomes an instrument of effective leadership. 
Guthrie and Neumann (2007) encapsulate effective leadership into nine ways of being (being present, aware, calm, focused, clear, equanimous, positive, compassionate, and impeccable). Utilising the essentials of a mindful, servant leadership model with Indigenous culture requires vision and cultural knowledge in order to get the best behavioural fit for leader, workplace, and community.

Kotter (1996) defined vision, which was identified above as an essential component of being a mindful servant-leader, as aspirational. While aspirational leadership models are not novel (e.g. Snedden, 1930; Murphy, 1941), they are forward-looking (Koning \& Waistall, 2012), and require leaders to have a vision for their community and/or organisation. They are also allied to ethical behaviours in organisations (Koning \& Waistall, 2012), less concerned with individual success than with building and maintaining relationships and supporting development of positive cultures. This includes being able to be shared in such a way as to leave people desirous of being part of that future (Graetz, 2000). Combining aspirational or visionary leadership with servant models, then, provides an important means of reinforces Sinclair's (2014) model of mindful leadership, particularly in relation to mobilising and supporting others in a way that is deeply present and connected.

\section{Towards an Indigenist Aspirational Model of Mindful Leadership}

Using epistemology from indigenist research, where a localised model is necessary (Rigney, 2001; 2006a, 2006b), distilling theories of leadership from Indigenous and non-Indigenous academics results in an indigenist model of leadership that is based on core values that wrap around the core activities of leading. In a similar fashion to indigenist research with Indigenous issues, an indigenist leadership model for Indigenous people, or for people working with Indigenous communities, will add to the effectiveness of that leadership.

The proposed model has the interview participants' preferred core values of a leader - courage, integrity, service and unconditional positive regard — informing the behaviours of indigenist servant leadership, with the individual leader's mindfulness attributes at the centre of the leader's conduct (see Fig. 8.3). Overall, the model is a set of attributes, skills and behaviours that leaders need to aspire to acquire.

\section{Additional Benefits of an Indigenist Aspirational Model}

Leading as a function of mindfulness will create push-up/pull-up motivational grids. Using this model will foster individuals to be the best they can be and encourage community cohesion by celebrating success, whoever owns it. In this way, leadership models can be vehicles of social inclusion. Social exclusion is a reliable 


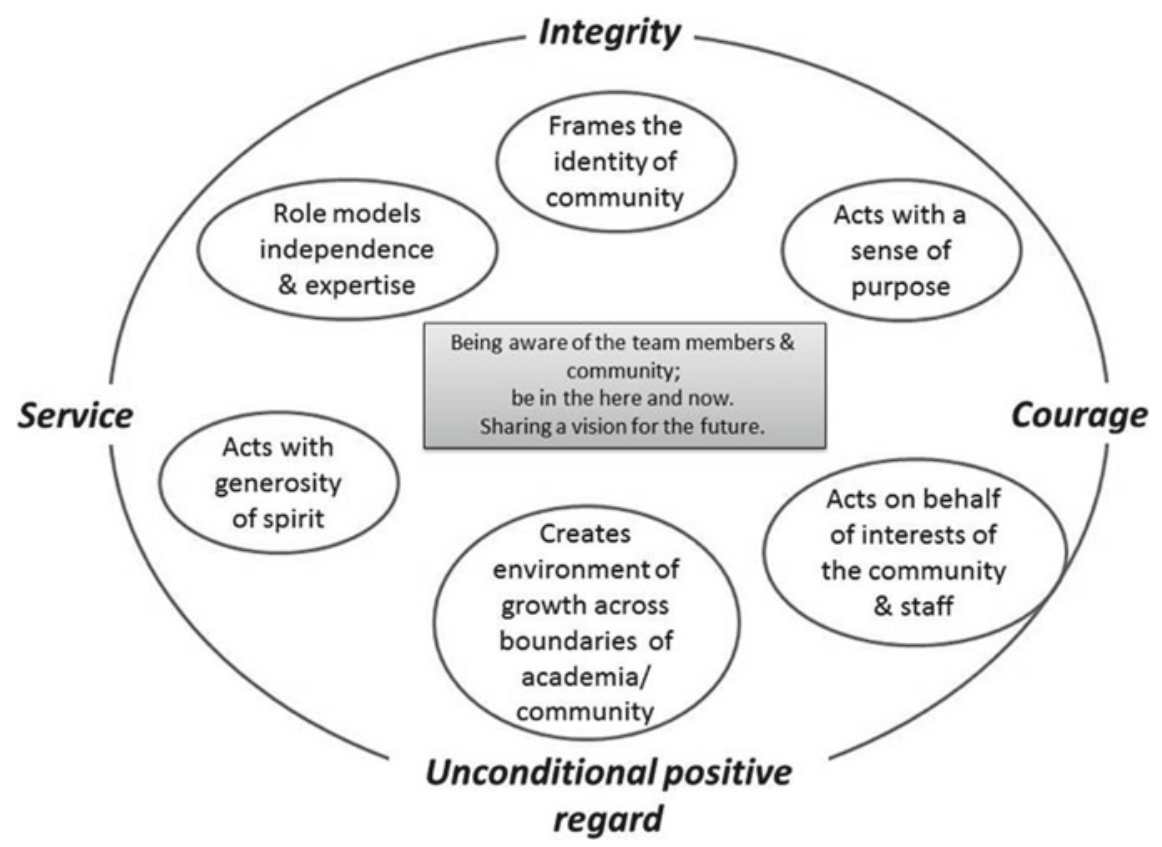

Fig. 8.3 An indigenist model of leadership

predictor of psychological distress (Butterworth, Leach, Pirkis, \& Kelaher, 2012), so opening up leadership positions by creating mentoring opportunities (e.g. rotating chair positions at community meetings), keeping processes transparent, and organisational structures 'flat', can create formal and informal learning opportunities, and incidental succession planning for community leadership.

\section{Conclusion}

The purpose of leadership is to work with others to improve the situation, whatever that situation may be. This indigenist aspirational model of modified servant leadership and applied mindfulness is aligned with cultural protocols (service, suggesting collectivist values), professional and personal ethics (integrity, courage) and an understanding of the need to create safe spaces for Indigenous peoples in academic settings, by creating unconditional positive regard. Indigenous academic leaders may find this model useful, as it allows one to maintain cultural integrity, and fulfil the obligations and responsibilities of an organisation, and better serve their Indigenous colleagues and communities. Further research that explores the challenges of merging workplace and indigenous expectations for indigenous leaders, and that modifies leadership models to best fit indigenous leaders and communities is necessary. 


\section{References}

Akuamoah-Boateng, R., Bolitho, F. H., Carr, S. C., Chidgey, J. E., O’Reilly, B., Phillips, R., ... \& Rugimbana, R. O. (2003). Psychosocial barriers to female leadership: Motivational Gravity in Ghana and Tanzania. Psychology and Developing Societies, 15(2), 201-221.

Asmar, C., Mercier, O. R., \& Page, S. (2009). You do it from your core: Priorities, perceptions and practices of research among Indigenous academics in Australian and New Zealand universities. In A. Brew \& C. Lucas (Eds.), Academic research and researchers (pp. 146-160). Maidenhead: Open University Press.

Attridge, M. (2009). Measuring and managing employee work engagement: A review of the research and business literature. Journal of Workplace Behavioral Health, 24(4), 383-398.

Australian Government. (2011). Review of higher education access and outcomes for Indigenous and Torres Strait Islander people. Canberra: Department of Industry.

Bailey, P. (2012). Learning an Indigenous model of service: Understanding Indigenous history and community. Domestic Violence Resource Centre Quarterly, 3(4), 30-31.

Bennis, W. G., \& Thomas, R. G. (2002). Crucibles of Leadership. Harvard Business Review, 60-69.

Bienen, H. S. (2012). The financial future of research universities. Social Research: An International Quarterly, 79(3), 631-634.

Boffa, J., King, M., McMullin, K., \& Long, R. (2011). A process for the inclusion of Indigenous People in health research: Lessons from the Determinants of TB Transmission project. Social Science and Medicine, 72(5), 733-738.

Bolden, R. (2004). What is leadership? University of Exeter: Regional Development Agency Research Report.

Bolden, R., Gosling, J., O'Brien, A., Peters, K., Ryan, M., Haslam, A., ... Winklemann, K. (2012). Academic leadership: Changing conceptions, identities and experiences in UK higher education Series 3, Pub 4. Exeter, UK. London: Leadership Foundation for Higher Education.

Bolden, R., Hawkins, B., Gosling, J., \& Taylor, S. (2011). Theoretical perspectives on leadership. In Exploring leadership: Individual organizational and societal perspectives (pp. 17-41). Oxford: Oxford University Press.

Braun, V., \& Clarke, V. (2006). Using thematic analysis in psychology. Qualitative Research in Psychology, 3(2), 77-101.

Brown, K. W., \& Ryan, R. M. (2003). The benefits of being present: Mindfulness and its role in psychological well-being. Journal of Personality and Social Psychology, 84(4), 822-842.

Buchele, B. J. (2011). The good leader. International Journal of Group Psychotherapy, 61(2), 285-292.

Burke, B. F., Cho, C. L., \& Wright, D. S. (2008). Continuity and change in executive leadership: Insights from the perspectives of state administrators. Public Administration Review, 68(s1), S29-S36.

Butterworth, P., Leach, L. S., Pirkis, J., \& Kelaher, M. (2012). Poor mental health influences risk and duration of unemployment: A prospective study. Social Psychiatry and Psychiatric Epidemiology, 47(6), 1013-1021.

Carr, S. C. (1995). Generating the velocity to overcome motivational gravity in LDC business organizations. Journal of Transnational Management Development, 1(2), 33-56.

Carr, S. C. (2006). Globalization and culture at work: Exploring their combined globality. Berlin: Springer Science \& Business Media.

Carr, S. C., \& MacLachlan, M. (1997). Motivational gravity. In D. Munro, J. F. Schumaker, \& S. C. Carr (Eds.), Motivation and culture (pp. 133-158). New York: Routledge.

Carr, S. C., MacLachlan, M., Zimba, C. G., \& Bowa, M. (1995). Managing motivational gravity in Malawi. The Journal of Social Psychology, 135(5), 659-662.

Cheers, B., Binell, M., Coleman, H., Gentle, I., Miller, G., Taylor, J., \& Weetra, C. (2006). Family violence: An Australian indigenous community tells its story. International Social Work, 49(1), $51-63$. 
Ciulla, J. B. (2013). Leadership ethics. In The international encyclopedia of ethics. Online. Blackwell Publishing Ltd. https://doi.org/10.1002/9781444367072.wbiee370

Detsky, A. S. (2010). How to be a good academic leader. Journal of General Internal Medicine, 26(1), 88-90.

Dotlich, D. L., Noel, J. L., \& Walker, N. (2011). Leadership passages: The personal and professional transitions that make or break a leader (Vol. 46). San Francisco: Wiley.

Doyle, K. (2011). Modes of colonisation and patterns of contemporary mental health: Towards an understanding of Canadian indigenous, Australian indigenous and Maori peoples. Indigenous and Islander Health Worker Journal, 35(1), 20-37.

Feather, N. T. (1994). Attitudes toward high achievers and reactions to their fall: Theory and research concerning tall poppies. Advances in Experimental Social Psychology, 26, 1-73.

Fereday, J., \& Muir-Cochrane, E. (2006). Demonstrating rigor using thematic analysis: A hybrid approach to inductive and deductive coding and theme development. International Journal of Qualitative Methods, 5(1), 80-92.

Fernandes, K. (2009). A course on Kanyini with Uncle Bob Randall, Mutitjulu, Uluru. New Community Quarterly, 7(3), 67.

Fletcher, F. R., Shannon, C., \& Dunbar, T. E. (2008). The National Health and Medical Research Council Road Map: A strategic framework for improving Aboriginal and Torres Strait Islander health through research. The Medical Journal of Australia, 188(9), 525-526.

Foley, D. (2003). Indigenous epistemology and Indigenous standpoint theory. Social Alternatives, 22(1), 44-52.

Fredericks, B. (2009). The epistemology that maintains white race privilege, power and control of Indigenous studies and Indigenous peoples' participation in universities. ACRAWSA E-journal, 5(1), 1-12.

Gächter, S., Nosenzo, D., Renner, E., \& Sefton, M. (2012). Who makes a good leader? Cooperativeness, optimism, and leading-by-example. Economic Inquiry, 50(4), 953-967.

Goleman, D., Welch, S., \& Welch, J. (2012). What makes a leader? LA: Findaway World LLC.

Gooda, M. (2007). Lateral violence in Indigenous and Torres Strait Islander communities. Social Justice Report. Canberra: Commonwealth of Australia.

Graetz, F. (2000). Strategic change leadership. Management Decision, 38(8), 550-562.

Greenleaf, R. K. (1977). Servant leadership: A journey into the nature of legitimate power and greatness (1st ed.). NY: Paulist Press.

Grint, K. (2004). What is leadership? From hydra to hybrid. Working paper, Said Business School and Green Templeton College, Oxford University.

Gunstone, A. (2008). Australian university approaches to Indigenous policy. The Australian Journal of Indigenous Education, 37(S), 103.

Guthrie, J., \& Neumann, R. (2007). Economic and non-financial performance indicators in universities: The establishment of a performance-driven system for Australian higher education. Public Management Review, 9(2), 231-252.

Jamieson, L. M., Paradies, Y. C., Eades, S., Chong, A., Maple-Brown, L. J., Morris, P. S., .... Brown, A. (2012). Ten principles relevant to health research among Indigenous Australian populations. The Medical Journal of Australia, 197(1), 16-18.

Jogulu, U. D. (2010). Culturally-linked leadership styles. Leadership and Organization Development Journal, 31(8), 705-719.

Johnson, S. L., \& Rea, R. E. (2009). Workplace bullying: Concerns for nurse leaders. Journal of Nursing Administration, 39(2), 84-90.

Kenny, C. B. (2004). A holistic framework for indigenous policy research funded by status of women Canada policy research fund. Ontario: Status of Women Canada.

Kenny, C. B. (2006). When the women heal: Indigenous women speak about policies to improve the quality of life. American Behavioral Scientist, 50(4), 550-561.

Kenny, C. B. (2012). Liberating leadership theory. In C. Kenny \& T. Fraser (Eds.), Living indigenous leadership: Native narratives on building strong communities (pp. 10-14). Vancouver: UBC Press. 
Koning, J., \& Waistell, J. (2012). Identity talk of aspirational ethical leaders. Journal of Business Ethics, 107(1), 65-77.

Kotter, J. (1996). Leading change. Massachusetts: Harvard Business School Press.

Kouzes, J. M., \& Posner, B. Z. (2011). Credibility: How leaders gain and lose it, why people demand it. LA: Wiley.

Kowanko, I., Stewart, T., Power, C., Fraser, R., Love, I., \& Bromley, T. (2009). An Indigenous family and community healing program in metropolitan Adelaide: Description and evaluation. Australian Indigenous Health Bulletin, 9(4), 1-12.

Langton, M. (2008). The end of "big men" politics. Griffith Review, 22, 48-57.

Laverack, G., Hill, K., Akenson, L., \& Corrie, R. (2009). Building capacity towards health leadership in remote Indigenous communities in Cape York. Australian Indigenous Health Bulletin, 9(1), $1-11$.

Lockwood, N. R. (2007). Leveraging employee engagement for competitive advantage. SHRM Research Quarterly, 52(3), 1-12.

MacBeath, J., \& Dempster, N. (Eds.). (2008). Connecting leadership and learning: Principles for practice. Abington: Routledge.

Martin, K. (2003). Ways of knowing, being and doing: A theoretical framework and methods for Indigenous and indigenist research. In K. McWillian, P. Stephenson, \& G. Thompson (Eds.), Voicing dissent (pp. 203-257). Brisbane: University of Queensland Press.

McCalman, J., Tsey, K., Kitau, R., \& McGinty, S. (2012). Bringing us back to our origin: Adapting and transferring an Indigenous Australian values-based leadership capacity-building course for community development in Papua New Guinea. Community Development, 43(3), 393-408.

McClelland, D. C. (1987). Human motivation. New York: Cambridge University Press.

McIlwaine, C., \& Moser, C. O. (2001). Violence and social capital in urban poor communities: Perspectives from Colombia and Guatemala. Journal of International Development, 13(7), 965984.

Middlehurst, R. (2013). Changing internal governance: Are leadership roles and management structures in United Kingdom universities fit for the future? Higher Education Quarterly, 67(3), 275-294.

Moll, J., \& Hoque, Z. (2011). Budgeting for legitimacy: The case of an Australian University. Accounting, Organizations and Society, 36(2), 86-101.

Moreton-Robinson, A. (2013). Towards an Australian indigenous women's standpoint theory: A methodological tool. Australian Feminist Studies, 28(78), 331-347.

Munro, D., Schumaker, J. F., \& Carr, S. C. (2014). Motivation and culture. Routledge.

Müller, R., \& Turner, R. (2010). Leadership competency profiles of successful project managers. International Journal of Project Management, 28(5), 437-448.

Murphy, A. J. (1941). A study of the leadership process. American Sociological Review, 674-687.

Nakata, M. (1998). Anthropological texts and Indigenous standpoints. Australian Indigenous Studies, 2, 3-12.

Naquin, V., Manson, S., Curie, C., Sommer, S., Daw, R., Maraku, C., ... Deaux, E. (2008), Indigenous evidence-based effective practice model: Indigenous leadership in action. The International Journal of Leadership in Public Services, 4(1), 14-24.

Parker, C., \& Aitken, L. (2011). The Queensland workplace culture check: Learning from reflection on ethics inside Law Firms. Georgetown Journal of Legal Ethics, 24, 399-421.

Petchsawang, P., \& Duchon, D. (2012). Workplace spirituality, meditation, and work performance. Journal of Management, Spirituality and Religion, 9(2), 189-208.

Pipe, T., \& Bortz, J. (2009). Mindful leadership as healing practice: Nurturing self to serve others. International Journal for Human Caring, 13(2), 34-38.

Prati, L. M., Douglas, C., Ferris, G. R., Ammeter, A. P., \& Buckley, M. R. (2003). Emotional intelligence, leadership effectiveness, and team outcomes. International Journal of Organizational Analysis, 11(1), 21-40. 
Priest, K., King, S., Brown, W. N., Nangala, I., \& Nangala, M. (2007). Warrki Jarrinjaku Jintangkamanu Purananjaku "working together everyone and listening": Aboriginal child rearing in remote central Australia. Canadian Journal of Native Education, 30(1), 61-74.

Rigney, L. I. (2006a). Indigenist research and Indigenous Australia. In J. Kunnie \& N. Goduka (Eds.), Indigenous peoples' wisdom and power: Affirming our knowledge through narratives (2nd ed, pp. 57-85). Aldershot: Ashgate.

Rigney, L. I. (2006b). Indigenist research and aboriginal Australia. In Indigenous peoples' wisdom and power, 32-50. Bodmin, UK: Ashgate Publishing Limited.

Rigney, L. I. (2001). A first perspective of Indigenous Australian participation in science: Framing Indigenous research towards Indigenous Australian intellectual sovereignty. Kaurna Higher Education Journal, 7, 1-13.

Rundle-Gardiner, A., \& Carr, S. (2005). Quitting a workplace that discourages achievement motivation: Do individual differences matter? New Zealand Journal of Psychology, 34(3), $149-155$.

Santoro, N., \& Reid, J. A. (2006). "All things to all people": Indigenous teachers in the Australian teaching profession. European Journal of Teacher Education, 29(3), 287-303.

Schmid, K., Hewstone, M., \& Al Ramiah, A. (2011). Self-categorization and social identification: Making sense of us and them. In Theories in Social Psychology (pp. 211-231). Oxford: Blackwell Press.

Schnurr, S. (2008). Leadership discourse at work: Interactions of humour, gender and workplace culture. Basingstoke, U.K.: Palgrave Macmillan Ltd. ISBN 9780230201804.

Shannon, C., Shibasaki, S., \& Australian Health Ethics Committee. (2005). Keeping research on track: A guide for Aboriginal and Torres Strait Islander peoples about health research ethics (pp. 1-52). Canberra: Australian Government.

Sinclair, A. (2007). Leadership for the disillusioned: Moving beyond myths and heroes to leading that liberates. Sydney: Allen and Unwin.

Sinclair, A. (2014). Leadership and power. Paper given at the Indigenous research and Leadership Program, University of Melbourne, July 2014.

Sinkula, J. M., Baker, W. E., \& Noordewier, T. (1997). A framework for market-based organizational learning: linking values, knowledge, and behavior. Journal of the academy of Marketing Science, 25(4), 305-318.

Smith, L. T. (1999). Decolonizing methodologies: Research and indigenous peoples. London: Zed books.

Snedden, D. (1930). Aspirational notions of leadership. School and Society, 31, 661-664.

Spears, L. C. (2004). Practising servant-leadership. Leader to Leader, 34, 7-11.

Stainback, K., Ratliff, T. N., \& Roscigno, V. J. (2011). The context of workplace sex discrimination: Sex composition, workplace culture and relative power. Social Forces, 89(4), 1165-1188.

Stromquist, N. P., \& Monkman, K. (Eds.). (2014). Globalization and education: Integration and contestation across cultures. Maryland, USA: Randl Education.

Sun, P. Y., \& Anderson, M. H. (2012). Civic capacity: Building on transformational Australian leadership to explain successful integrative public leadership. The Leadership Quarterly, 23(3), 309-323.

Smith, B. J., \& Carr, S. C. (1997). Selection in Egalitarian Australia: Weighted Average or Motivational Gravity?. South Pacific Journal of Psychology, 9, 7-19.

Tajfel, H. (Ed.). (2010). Social identity and intergroup relations (vol. 7). Cambridge, UK: Cambridge University Press.

Taylor, B., \& Barling, J. (2004). Identifying sources and effects of carer fatigue and burnout for mental health nurses: A qualitative approach. International Journal of Mental Health Nursing, $13(2), 117-125$.

Thomas, D. R. (2016). A General Inductive Approach for Analyzing Qualitative Evaluation Data. American Journal of Evaluation, 27(2), 237-246.

Turney, L. (2003). Mental health and workplace bullying: The role of power, professions and "on the job" training. Advances in Mental Health, 2(2), 99-107. 
Vilkinas, T., \& Ladyshewsky, R. K. (2012). Leadership behaviour and effectiveness of academic program directors in Australian universities. Educational Management Administration and Leadership, 40(1), 109-126.

Voon, M. L., Lo, M. C., Ngui, K. S., \& Ayob, N. B. (2011). The influence of leadership styles on employees job satisfaction in public sector organizations in Malaysia. International Journal of Business, Management and Social Sciences, 2(1), 24-32.

Walker, M., Fredericks, B., Mills, K., \& Anderson, D. (2014). "Yarning" as a method for communitybased health research with indigenous women: The indigenous women's wellness research program. Health Care for Women International, 35(10), 1216-1226.

West, R., Stewart, L., Foster, K., \& Usher, K. (2012). Through a critical lens: Indigenist research and the Dadirri method. Qualitative Health Research, 22(11), 1582-1590.

White, N. (2009). University-educated Indigenous women: Their struggles and triumphs on their leadership journeys. In J. Frawley, M. R. Nolan, \& N. D. White (Eds.), Indigenous issues in Australian universities: Research, teaching, support (pp. 95-105). Darwin: Charles Darwin University Press.

White, N. (2010). Indigenous Australian women's leadership: Stayin' strong against the postcolonial tide. International Journal of Leadership in Education, 13(1), 7-25.

Wingard, B. (2010). A conversation with lateral violence. International Journal of Narrative Therapy and Community Work, 2010(1), 13-27.

Kerrie E. Doyle is the inaugural Professor of Indigenous Health in the School of Medicine at Western Sydney University, and leader of the Aboriginal and Torres Strait Islander Clinical Academic Group at the Sydney Partnership for Health, Education, Research and Enterprise. A social scientist and mental health clinician, she has over 40 years' experience working in Indigenous health and communities and has various research interests including her collaboration in the Global Burden of Disease project.

Catherine Hungerford is Head of the School of Nursing, Midwifery and Indigenous Health, Charles Sturt University. This School is located on multiple rural campuses, with over 2000 students and more than 60 staff, from diverse backgrounds. She has a keen interest in leadership models and culture and has worked extensively with Aboriginal Australians.

Chris Pitt is a Project Officer within Maridulu Budyari Gumal and works closely with Aboriginal and Torres Strait Islander researchers. He has qualifications in psychology and public health. His research interest is in the field of health informatics, and Indigenous Health.

Paul Saunders is a Biripi man with connections to the Kamilaroi nation. He holds a Bachelor of Medicine, Bachelor of Surgery (MBBS) and is currently undertaking a Master of Public Health (MPH), Western Sydney University. Paul is a research fellow for Indigenous Health at THRI and also an Honorary Fellow of Ngarruwan Ngadju, the University of Wollongong's First People's Health and Wellbeing Research Centre.

Kyar Wilkey is a Ngarrindjeri woman from South Australia. Her educational background includes a Bachelor of Psychological Science (Honours). She is a Research Assistant at Western Sydney University with the Translational Health Research Institute and Maridulu Budyari Gumal. Kyar's research interests relate to Aboriginal and Torres Strait Islander health and wellbeing. 
Open Access This chapter is licensed under the terms of the Creative Commons Attribution 4.0 International License (http://creativecommons.org/licenses/by/4.0/), which permits use, sharing, adaptation, distribution and reproduction in any medium or format, as long as you give appropriate credit to the original author(s) and the source, provide a link to the Creative Commons license and indicate if changes were made.

The images or other third party material in this chapter are included in the chapter's Creative Commons license, unless indicated otherwise in a credit line to the material. If material is not included in the chapter's Creative Commons license and your intended use is not permitted by statutory regulation or exceeds the permitted use, you will need to obtain permission directly from the copyright holder.

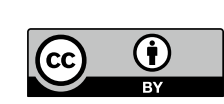

